\title{
Brainstem anaesthesia after peribulbar anaesthesia
}

Renato S. Gomez MD MSC,

L.O.F Andrade $M D$,

J.R. Rezende Costa MD

Purpose: To present a case of brainstem anaesthesia as a complication of peribulbar anaesthesia.

Clinical features: A 75-yr-old woman received peribulbar anaesthesia for cataract surgery. A few seconds after the block was performed, she had a respiratory arrest, became unconscious, and developed hypertension and tachycardia followed by hypotension and bradycardia. Ventilatory and haemodynamic support were performed before the patient regained adequate spontaneous breathing, and normal heart rate and blood pressure.

Conclusion: Peribulbar anaesthesia generally carries a low risk of serious complications. However, respiratory arrest and brainstem anaesthesia may occur as complications of peribulbar blocks.

Objectif : Présenter un cas d'anesthésie du tronc cérébral compliquant une anesthésie péribulbaire

Éléments cliniques : Un bloc péribulbaire était réalisé chez une femme de 75 ans pour l'extraction d'une cataracte. Quelques secondes après linjection, la patiente cessait de respirer et perdait conscience. Elle devenait hypertendue et tachycarde puis hypotendue et bradycarde. La ventilation et la circulation devaient être supportées jusqu'au retour spontané à la normale.

Conclusion : En général, l'anesthésie péribulbaire comporte un faible risque de complications sérieuses. Un arrêt respiratoire par anesthésie du tronc cérébral est toujours possible.

From the Departamento de Cirurgia - Faculdade de Medicina UFMG, Hospital das Clínicas UFMG, Belo Horizonte, Minas Gerais, Brasil. Address correspondence to: Dr. Renato Santiago Gomez, Departamento de Farmacologia -ICB-UFMG, Caixa Postal, 2486,

31160-970-Belo Horizonte-MG-Brasil. Fax: +55314410835 .

Accepted for publication April 20, 1997 
A WIDE variety of eye surgery is performed with regional anaesthesia. Retrobulbar anaesthesia was first described in $1884^{1}$ but it occasionally produces serious complications. The introduction of peribulbar anaesthesia ${ }^{2}$ offers another option which is probably safer than retrobulbar anaesthesia. Previous reports have focused on the demonstration of the safety of peribulbar anaesthesia. ${ }^{2-3}$ Indeed, peribulbar anaesthesia seems to be associated with a lower incidence of complications such as inadvertent penetration of the globe, optic nerve or blood vessels. ${ }^{3}$

In this report, we describe respiratory arrest with haemodynamic changes and brainstem anaesthesia after peribulbar anaesthesia.

\section{Case report}

A 75-yr-old woman presented for elective cataract surgery of the right eye. Coronary artery disease was diagnosed $15 \mathrm{yr}$ earlier and she had been using 25 $\mathrm{mg} \cdot \mathrm{day}^{-1}$ captopril for chronic hypertension. There was no other :nedical history. Preoperative anaesthetic examination revealed a $160 \mathrm{~cm}, 70-\mathrm{kg}$ woman with a normal airway. Results of laboratory studies were unremarkable. The night before surgery, $5 \mathrm{mg}$ diazepam po was given as premedication. Standard monitoring was used.

Peribulbar anaesthesia was administered using a 22gauge, $2.5 \mathrm{~cm}$, sharp, disposable needle. The anaesthetic consisted of a 50/50 mixture of lidocaine $1.0 \%$ and bupivacaine $0.5 \%$ with $50 \mathrm{U} \cdot \mathrm{ml}^{-1}$ hyaluronidase; the total volume of the mixture was $10 \mathrm{ml}$. After the eyelids were prepared with an alcohol pad and ensuring that the eye was kept in the primary gaze position, the needle was introduced through the skin of the lower-lid sulcus at the inferolateral angle of the orbit. The needle was inserted along the orbital wall to a depth of $2.5 \mathrm{~cm}$. Possible intravascular injection was excluded by aspiration. Six millilitres of the anaesthetic mixture were injected. No second injection site (supero-medial) was done. A few seconds later, the patient became unconscious, apnoeic, cyanotic, hypertensive and tachycardic, followed by the development of hypotension and bradycardia. Ventilatory assistance by mask and oxygen was initially performed but, as she did not regain adequate spontaneous breathing, the trachea was intubated. Atropine $(1.0 \mathrm{mg}$ ) and ephedrine ( $5 \mathrm{mg}+5 \mathrm{mg}$ ) were used to control bradycardia and hypotension, respectively. During this time, she was unresponsive to pain and had no reflexes. After nearly $40 \mathrm{~min}$, she started to breathe spontaneously, and slowly regained consciousness. Shortly thereafter, she was fully conscious and the endotracheal tube was removed. She had no recall of the incident. The surgical procedure began with the right eye anaesthetized, with no serious residual effects. The peribulbar block resolved completely in eight hours. Postoperatively, she had no complaints and was discharged two days after the procedure.

\section{Discussion}

In an attempt to reduce the complications associated with retrobulbar anaesthesia, peribulbar blocks were introduced in $1986 .{ }^{2}$ Peribulbar anaesthesia produces optimal conditions for the performance of ophthalmic surgery and has been shown to result in less pain during its administration and fewer perioperative complications than retrobulbar anaesthesia, such as brainstem anaesthesia, retrobulbar haemorrhage and scleral perforation. ${ }^{2-4}$ However, the risk of peribulbar haemorrhage ${ }^{5}$ and perforation of the globe ${ }^{6}$ is not abolished with the peribulbar technique.

To our knowledge, the possibility of brainstem anaesthesia and respiratory arrest have been reported occasionally after peribulbar block. ${ }^{7,8}$ Attention has been focused on ocular position when regional anaesthesia of the eye is performed, in an attempt to avoid intrathecal injection and optic-nerve injury. With the globe in superonasal gaze, the optic nerve and the subdural space are in close proximity to the introduced needle. ${ }^{9,10}$ In this position, the needle tip can reach the meningeal sheath surrounding the optic nerve, allowing local anaesthetic to diffuse towards the subarachnoid space. In keeping the globe in a positing primary gaze, the optic nerve sheath is less vulnerable to needle penetration. ${ }^{11}$ Another important factor is the length and type of needle selected. Many authors suggest using sharp, fine disposable needles no longer than $25 \mathrm{~mm}$ to decrease the consequences of inadvertent globe puncture..$^{8,12}$

The technique of peribulbar anaesthesia performed in the present case has been used by several authors without severe complications. ${ }^{2,4,13}$ Two mechanisms are proposed to explain the complications observed in this patient. First, access to the brain could have been by direct injection into the subarachnoid space and the respiratory arrest would occur after a few minutes. ${ }^{3,9,14}$ Second, an inadvertent intra-arterial injection could have produced retrograde flow through the ophthalmic artery into the internal carotid artery. Then, local anaesthetic would have been delivered to the thalamus and other midbrain structures, inducing immediate central nervous symptoms such as respiratory arrest and haemodynamic changes. ${ }^{3,15}$ In the pre- 
sent case, the first symptoms and signs of brainstem anaesthesia appeared a few seconds after the peribulbar anaesthesia procedure began. Thus, the immediacy of these signs and symptoms suggest that the second mechanism is more likely to have been responsible for the complication despite the absence of intravascular injection demonstrated by a negative aspiration. However, the clinical picture resulting from intra-arterial injection is the immediate onset of grand mal seizure activity as the predominant sign. ${ }^{16}$ The absence of grand mal seizure activity does not exclude the second mechanism described above as direct deposition of local anaesthetic to the brain structures after inadvertent intra-arterial injection could induce electrical silence without grand mal seizure activity. ${ }^{15}$

In conclusion, we present a case of respiratory arrest and brainstem anaesthesia after peribulbar anaesthesia. Even if the possibility of complication is lower with peribulbar anaesthesia than with retrobulbar blocks, with the increasing use of this technique, more complications will occur.

\section{Acknowledgments}

We thank Dr. De Marco and Dr. J. R. Nicoli for reading and suggestions in this manuscript. Supported by Fapemig.

\section{References}

1 Knapp H. On cocaine and its use in ophthalmic and general surgery. Arch Ophthalmol 1884; 13: 402-48.

2 Davis DB II, Mandel MR. Posterior peribulbar anesthesia: an alternative to retrobulbar anesthesia. J Cataract Refract Surg 1986; 12: 182-4.

3 Wong $D H W$ Regional anaesthesia for intraocular surgery. Can J Anaesth 1993; 40: 635-57.

4 Murdoch IE. Peribulbar versus retrobulbar anaesthesia. Eye 1990; 4: 445-9.

5 Ortiz $M$, Valls $R$, Vallés J, Blanco $D$, Vidal $F$. Topography of peribulbar anesthesia. Reg Anesth $1995 ; 20: 337-42$

6 Kimble JA, Morris RE, Witherspoon CD, Feist RM. Globe perforation from peribulbar injection (Letter). Arch Ophthalmol 1987; 105: 749.

7 Zabl K, Nassif JM, Meltzer MA, Som P. Simulated peribulbar injection of anesthetic. Ann Ophthalmol 1991; 23: 114-7.

8 Pannu JS. Peribulbar vs. retrobulbar anesthetic techniques (Letter). Ophthalmic Surg 1990; 21: 147-50

9 Drysdale DB. Experimental subdural retrobulbar injection of anesthetic. Ann Ophthalmol 1984; 16: 716-8.
10 Unsild R, Stanley JA, DeGroot J. The CT-topography of retrobulbar anesthesia. Graefes Arch Klin Exp Ophthalmol 1981; 217: 125-36.

11 Liu C, Youl B, Moseley I. Magnetic resonance imaging of the optic nerve in extremes of gaze. Implications for the positioning of the globe for retrobulbar anaesthesia. Br J Ophthalmol 1992; 76: 728-33.

12 Hamilton RC, Gimbel HV, Strunin L. Regional anaesthesia for 12,000 cataract extraction and intraocular lens implantation procedures. Can J Anaesth 1988; 35: 615-23.

13 Whitsett JC, Balyeat HD, McClure B. Comparison of one-injection-site peribulbar anesthesia and retrobulbar anesthesia. J Cataract Refract Surg 1990; 16: 243-5.

14 Hamilton RC. Brain-stem anesthesia as a complication of regional anesthesia for ophthalmic surgery. Can J Ophthalmol 1992; 27: 323-5.

15 Rosenblatt RM, May DR, Barsoumian $K$. Cardiopulmonary arrest after retrobulbar block. Am J Ophthalmol 1980; 90: 425-7.

16 Meyers EF, Ramirez RC, Boniuk I. Grand mal seizures after retrobulbar block,. Arch Ophthalmol 1978; 96: 847. 